\title{
Non-Newtonian Behavior of Low Density Polyethylene Melts
}

\author{
by \\ Masaharu Kumazaki, Isamu Shiga and Atsushi Hashimoto \\ (Polymer Research Laboratory, Mitsubishi Chemical \\ Ind. Ltd., Kamoshida, Midori-ku, Yokohama)
}

\begin{abstract}
Non-Newtonian behavior of low density polyethylene melts was studied at $190^{\circ} \mathrm{C}$ in a wide range of shear rate $\dot{\gamma}$, namely from $1 \times 10^{-2}$ to $3 \times 10^{3} \mathrm{sec}^{-1}$. Three types of commercial low density resins were fractionated carefully to obtain sharp fractions of branched polyethylenes, $\mathrm{AF}, \mathrm{BF}$ and $\mathrm{CF}$ series, respectively, and one type of commercial high density resin to obtain a series of linear polyethylenes, HDPE fractions, as reference materials. The weight-average molecular weight of low density polyethylene fractions was determined by light scattering. The melt viscosities $\eta$ of low and high density polyethylene fractions were measured by using a cone-plate type rheometer in the range of low shear rate and a capillary type rheometer in the range of high shear rate. The zero shear viscosity $\eta_{0}$ of the high density polyethylene fractions was proportional to $M_{v}^{3.53}$. The zero shear viscosities of two series ( $\mathrm{AF}$ and $\mathrm{BF}$ series) of branched polyethylene fractions were higher than that of the linear polyethylene fractions of the same molecular weight in the range of molecular weight higher than $5 \times 10^{4}$, while $\eta_{0}$ of the third series (CF series) of branched polyethylene fractions was always lower than that of the linear polyethylene fractions of the same molecular weight. The reduced viscosity $\eta / \eta_{0}$ of branched polyethylene fractions was not a unique function of $\tau_{\mathrm{B}} \dot{\gamma}$, but was a function of $g_{1} \tau_{\mathrm{B}} \dot{\gamma}$. Here $\tau_{\mathrm{B}}$ is the Bueche relaxation time and $g_{1}$ is the branching index calculated by the Zimm-Kilb equation. The dependence of $\eta / \eta_{0}$ on the quantity $g_{1} \tau_{\mathrm{B}} \dot{\gamma}$ was given by the modified Bueche-Harding equation, $\eta / \dot{\gamma}_{0}=1 /\left[1+0.6\left(g_{1} \tau_{\mathrm{B}} \dot{\gamma}\right)^{0.75}\right]$ for $\mathrm{AF}$ and BF series, and by a slightly different form for $\mathrm{CF}$ series.
\end{abstract}

\section{低密度ポリエチレン融液の非ニュートン挙動}

\author{
熊崎 昌治・志賀勇・橋本 淳*
}

（原稿受理：昭和50年1月29日）

\section{1. 緒言}

高分子物質の成形加工性を榆討するとき, 融液の非ニュートン 挙動を明らかにすることは非常に重要な問題であり, 最近までに 数多くの研究が報告されている。一般に直鎖高分子の非ニュート ン挙動恃分子量と分子量分布に依存し，分岐高分子に打いては更 に長鎖分岐の種類, 数执よび長さにも依存すると考えられる ${ }^{5)}$.

Bueche や Graessley の理論によると, 高分子融液の非ニュート ン举動は換算ずり速度と, 換算ずり粘度の 2 つ換算変数で 1 本 のマスターカーブに重社合せることができる ${ }^{9)}$ 11)，単分散ある

\footnotetext{
* 三菱化成工業(株)高分子研究所 横浜市緑区鴨志田町 1000
}

い恀分散值鎖高分子に括いてはこの事が確認されて扣り，また 分岐高分子に関しても検討されている. しかし，長鎖分岐を有す る低密度ポリエチレンの分子量分布の狭い試料について, 広いず り速度の範囲で検討した報告は少ない上うに思われる。

われわれは市販低密度ポリエチレンの分別物について, 広範囲 なずり速度で非ニュートン挙動について検討した。

\section{2. 実}

\section{験}

\section{$2 \cdot 1$ 定常ずり粘度の測定}

融液の定常ずり粘度の測定において，低ずり速度領域ではコー ン・プレート型粘度計（リオン製モデル1205A）を使用した。こ 
の場合には試料を充てんした後測定終了までにかなりの時間を要 するので， ポリエチレンの熱劣化を防止するために粘度計全体を 窒素シールのボックスに入れた。

高ずり速度領域では，定荷重式毛細管粘度計（島津製作所製高 化式フローテスター）を使用した。この場合には直径 D $0.5 \mathrm{~mm}$, 長さ $L 15 \mathrm{~mm}(L / D=30)$ の平型ノズルを使用した.

$L / D$ が30のノズルでは Bagley ${ }^{1)}$ 法による末端補正が必要でな いことをあらかじめ確認し，Rabinowitch2）の式によるずり速度 についての非ニュートン粘性の補正のみを行った.

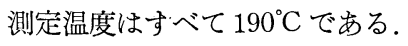

\section{$2 \cdot 2$ 試料および分子量の測定}

実験に使用した試料はチューブラータイプ( 1 種類), 特よびオ 一トクレーブタイプ( 2 種類)の市販低密度ポリエチレン (LDPE) の分別物であり，それぞれ $\mathrm{AF}, \mathrm{BF}, \mathrm{CF}$ シリーズとした．更に フィリップスタイプの市販高密度ポリエチレン (HDPE) 分別物 も使用した。

分別物はセライト545を担体とし，キシレンーエチルセルソルブ 混合溶媒系 $126^{\circ} \mathrm{C} て ゙, 100 \mathrm{~g}$ スケールのカラム分別により得た。 溶 液粘度はテトラリン中，高分子濃度 $0.1 \% ， 130^{\circ} \mathrm{C} て ゙$ 測定した（一 点測定). HDPE 分別物の 粘度平均分子量 $M_{v}$ は Tung3) の式 (1) から求めた.

$$
[\eta]=4.60 \times 10^{-4} M_{v}^{0.725}
$$

Table I 飞 LDPE 分別物の 極限粘度数 $[\eta]$, 重量平均分子量 $M_{w}$ の值を示す. 重量平均分子量 $M_{w}$ は島津製作所製の光散乱 測定装置 PG-21 型により， $\alpha$-クロロナフタレン中 $125^{\circ} \mathrm{C}$ で測定 した.

\section{3. 結果と考察}

\section{$3 ・ 1$ ゼロシアー粘度}

Fig. 1 に一例として, LDPE 分別物 AF シリーズの定常ずり 粘度クのずり速度 $\dot{\gamma}$ 依存性を示す。ずり速度が特よそ $1 \times 10^{-2}$ 〜 $5 \times 10^{0}\left(\mathrm{sec}^{-1}\right)$ の範囲はコーン・プレート型粘度計で測定した結 果であり，これ以上のずり速度では毛細管粘度計により測定した

Table I. Characterization data and zero shear viscosity of low density polyethylene fractions

\begin{tabular}{cccc}
\hline Sample & {$[\eta]$} & $M_{w} \times 10^{-4}(\mathrm{LS})$ & $\eta_{0} \times 10^{-4}$, Poise \\
\hline AF 12 & 0.63 & 5.46 & 0.44 \\
AF 13 & 0.78 & 6.21 & 1.70 \\
AF 14 & 0.89 & 7.14 & 4.6 \\
AF 15 & 0.94 & 10.4 & 17.6 \\
AF 16 & 1.08 & 15.4 & 80 \\
\hline BF 12 & 0.66 & 3.65 & 0.185 \\
BF 13 & 0.76 & 5.35 & 0.65 \\
BF 14 & 0.83 & 5.84 & 1.65 \\
BF 15 & 0.89 & 6.94 & 4.3 \\
BF 16 & 0.96 & 8.93 & 12.0 \\
\hline CF 13 & 0.74 & 6.60 & 0.64 \\
CF 14 & 0.79 & 7.58 & 1.62 \\
CF 15 & 0.90 & 11.1 & 3.9 \\
\hline
\end{tabular}

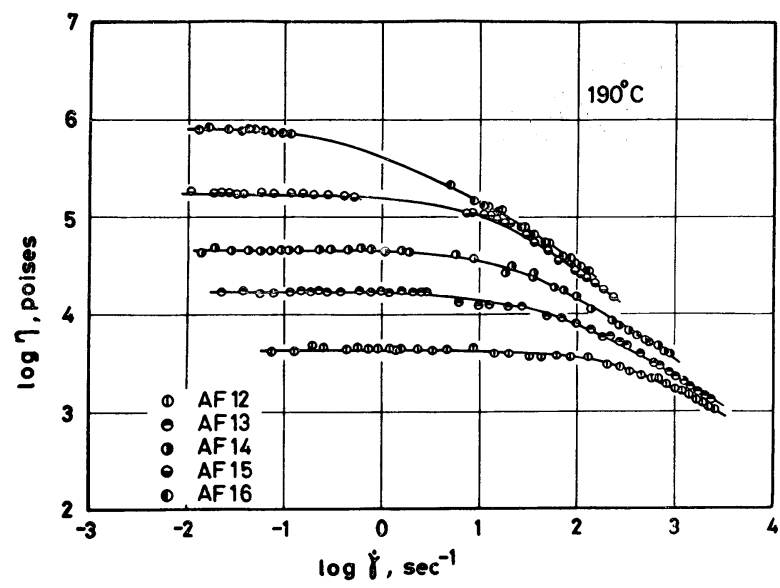

Fig. 1. Steady shear viscosity versus shear rate of low density polyethylene fractions $\mathrm{AF}$ series.

ものである. 試料のゼロシァー粘度 $\eta_{0}$ は，すべて Fig. 1 亿示

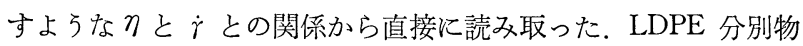
の $\eta_{0}$ は Table I にまとめた。

Fig. 2 にLDPE 分別物の ゼロシァー粘度 $\eta_{0}$ と分子量 $M_{w}$ の 関係を示す. 更に HDPE 分別物の $\eta_{0}$ と $M_{v}$ の関係も示したが, 本研究に用いた HDPE 分別物の $M_{v}$ は $M_{w}$ に注涪等しいと考 允られる. HDPE 分別物の $\eta_{0}$ は分子量の 3.53 乗に比例し, Mendelson4) らにより得られた結果によく一致する。

長鎖分岐を有する分岐高分子の $\eta_{0}$ は，同一分子量に打ける直 鎖高分子の $\eta_{0}$ よりも小さくなると言われている7). しかし，ある 分子量以上では，ポリブタジェン5)， ポリ酢酸ビニル6)の分岐高 分子は同一分子量を有する直鎖高分子に比べ大きな $\eta_{0}$ を示す。

長鎖分岐を有すると考兄られる LDPE 分別物の場合には Fig. 2 から分かるように同一分子量で，直鎖高分子である HDPE 分別 物に比較して, $\mathrm{CF}$ シリーズは小さな $\eta_{0}$ を示し， $\mathrm{AF}, \mathrm{BF}$ シリ 一ズは大きな $\eta_{0}$ を示す.

分岐高分子の粘度が，分子鎖の広がりによって決定されるとい $\zeta$ Bueche $^{7)}$ の理論に従って，分岐指数 $g$ を使用して $\eta_{0}$ を $g, M_{w}$ の関数として整理することを試みる. (Fig. 3)

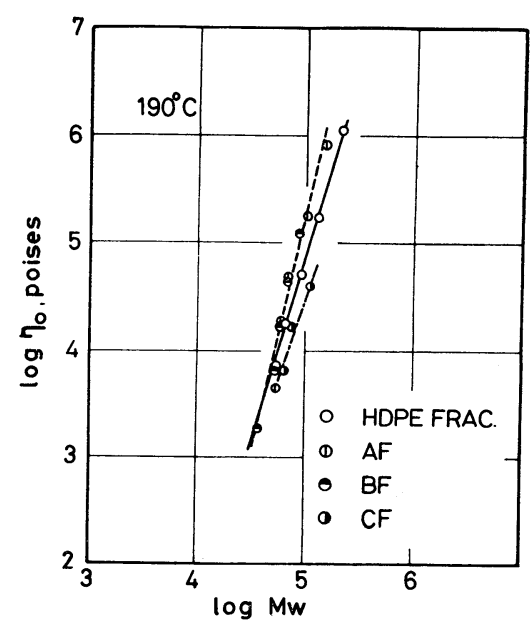

Fig. 2. Zero shear viscosity versus molecular weight of high density and low density polyethylene fractions. 


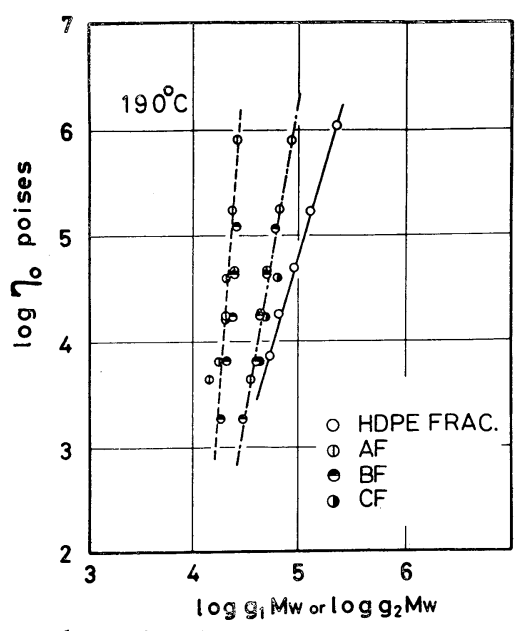

Fig. 3. Zero shear viscosity versus $g_{1} M_{w}$ or $g_{2} M_{w}$ of high density and low density polyethylene fractions.

$\cdots \ldots$... $\eta_{0}$ vs. $g_{1} M_{w}$,

-.-- $\eta_{0}$ vs. $g_{2} M_{w}$.

分岐指数 $g$ は Zimm-Stockmayer ${ }^{8)}$ により， $\theta$ 溶媒中での同一 分子量を有する分岐高分子拉よび直鎖高分子の慣性半径の 2 乘平 均 $\left\langle S^{2}\right\rangle_{\theta b},\left\langle S^{2}\right\rangle_{\theta l}$ から式 (2) で定義される量であり, ZimmKilb 理論16)17)拈よび Flory-Fox 理諭18)19)によりそれぞれ式 (3) 扣よび式（4）の関係が得られている。

$$
\begin{aligned}
& g=\left\langle S^{2}\right\rangle_{\theta b} \\
& \left\langle S^{2}\right\rangle_{\theta l} \\
& g_{1}{ }^{1 / 2}=\frac{[\eta]_{\theta b}}{[\eta]_{\theta l}} \\
& g_{2}{ }^{3 / 2}=\frac{[\eta]_{\theta b}}{[\eta]_{\theta l}}
\end{aligned}
$$

ここで, $[\eta]_{\theta b},[\eta]_{\theta l}$ は $\theta$-溶媒中での分岐扣よび直鎖高分子の 極限粘度数である.

本研究では $g_{1}, g_{2}$ は $130^{\circ} \mathrm{C}$ ，テトラリン中での $[\eta]$ から定義さ れるパラメータで, $g$ としてどちらが正しいかは問題にしない.

Fig. 3 から分かるように LDPE の $\log \eta_{0}$ は $\log g_{1} M_{w}$ と， あるいは $\log g_{2} M_{w}$ とほぼ直線関係にあるが，直線の傾きは 3.4 〜3.5 よりも大きく，それぞれ 13.1 および 5.7 である.

Mendelson $^{4}$ らによると, 式（3）から算出した分岐指数 $g_{1}$ を 使用したとき， $\eta_{0}$ は $g_{1} M_{w}$ の 6.56 乗比例するが本研究の結果 では $\eta_{0}$ は更に大きな $g_{1} M_{w}$ 依存性を示す。

\section{3 ・ 2 非ニュートン粘性}

Bueche $^{9)}$ や Graessley ${ }^{10) 11)}$ によると, 換算粘度 $\eta / \eta_{0}$ 対ずり速 度 $\dot{\gamma}$ の曲線を分子の最長緩和時間 $\tau$ を用いて， $\eta / \eta_{0}$ を $\tau \dot{\gamma}$ に対 してプロットすることにより，1本のマスターカーブに重ね合わ すことができるとされている．

マスターカーブに対して Bueche や Graessley の理論曲線のほ かに, Sabia ${ }^{12)}$ や Bueche, Harding ${ }^{13)}$ による半経験式が得られて いる. 式 (5) が Bueche, Harding による半経験式である.

$$
\begin{aligned}
\frac{\eta}{\eta_{0}} & =\frac{1}{1+0.6\left(\tau_{\mathrm{B}} \dot{\gamma}\right)^{0.75}} \\
\tau_{\mathrm{B}} & =\frac{12 \eta_{0} M}{\pi^{2} \rho R T}
\end{aligned}
$$

ここで， $\tau_{\mathrm{B}}$ は Bueche の緩和持間， $\rho$ は絶対温度 $T$ に扮ける高 分子の密度, $R$ はガス定数, $M$ は分子量である.

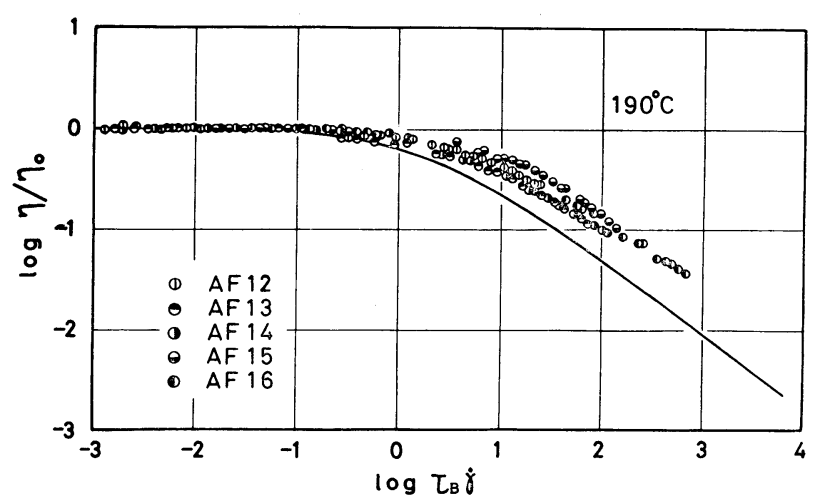

Fig. 4. Reduced viscosity $\eta / \eta_{0}$ versus reduced shear rate $\tau_{\mathrm{B}} \dot{\gamma}$ of fractions $\mathrm{AF}$ series.

— calculated by Bueche-Harding's equation.

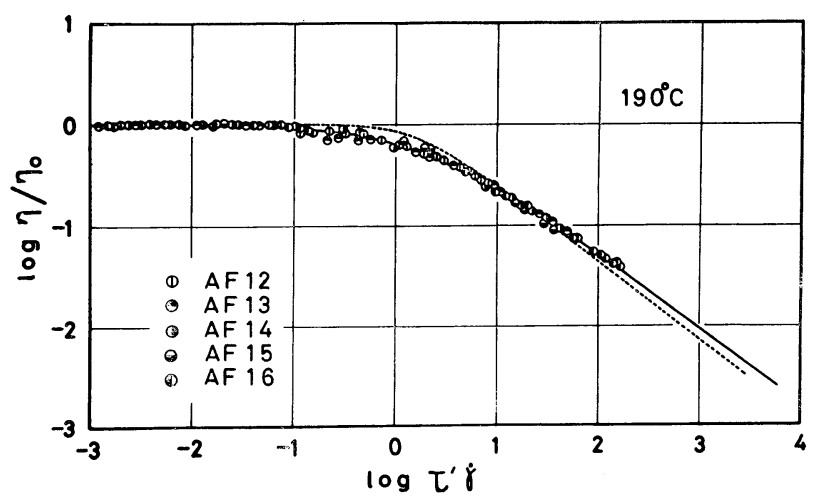

Fig. 5. The relation between $\eta / \eta_{0}$ and $\tau^{\prime} \dot{\gamma}$ of $\mathrm{AF}$ series with an arbitrary shift factor $\tau^{\prime}$.

— by Bueche-Harding's equation,

..... by Graessley's equation for monodisperse polymer.

Fig. 4 は $\mathrm{AF}$ シリーズの $\eta / \eta_{0}$ と $\tau_{\mathrm{B}} \dot{\gamma}$ の関係を示す. Fig. 4 から分かるように，緩和時間 $\tau_{\mathrm{B}}$ を用いたときは $\eta / \eta_{0}$ と $\dot{\gamma} の$ 関係を単一な曲線に重㸚わすことができない，浛かの $\mathrm{BF}, \mathrm{CF}$ シリーズについても同じである.

$\tau_{\mathrm{B}}$ の代りに $\dot{\gamma}$ に関する任意の移動因子 $\tau^{\prime}$ により, $\mathrm{AF}$ シリ 一ズの $\eta / \eta_{0}$ と $\dot{\gamma}$ の関係を式 (5) に重ね合わせたのが Fig. 5 で ある、ほかのシリーズの場合にも同じよ5に式 (5) に良く重叔合 わせることができる. Fig. 5 には比較のために Graessley の単分 散高分子に対する理論曲線を破線で示す。

Graessley, Prentice ${ }^{14)}$ による ，分岐ポり酢酸ビニルの非ニュ ートン挙動は Graessley 理論に一致する上されているが, Fig. 5 から，長鎖分岐を有する LDPE 分別物の場合には単分散高分子 に対する Graessley 理論には一致しない。

Fig. 6 は移動因子 $\tau^{\prime}$ の分子量依存性を示す. $\tau^{\prime}$ の分子量依存 性は Fig. 2 の $\eta_{0}$ と $M_{w}$ の関係に類似して扔り， $\tau^{\prime}$ を分子の緩 和時間に相当する量と考学る之， $\tau^{\prime}$ は $g_{1} M_{w}$ あるいは $g_{2} M_{w}$ の ベキ乗に比例することが推定される。 したがって， $\tau_{\mathrm{B}} \dot{\gamma} を g_{1} \tau_{\mathrm{B}} \dot{\gamma}$ または $g_{2} \tau_{\mathrm{B}} \dot{\gamma}$ にかえると $\eta / \eta_{0}$ 対 $\dot{\gamma}$ の曲線を 1 本のマスターカー ブで整理できると考兄られる.

Fig. 7 は AF シリーズの $\eta / \eta_{0}$ と $g_{2} \tau_{\mathrm{B}} \dot{\gamma}$ の関係を示す. この 場合は必ずしも良好な重ね合わせはできない， $\mathrm{AF}, \mathrm{BF}, \mathrm{CF}$ シリ 


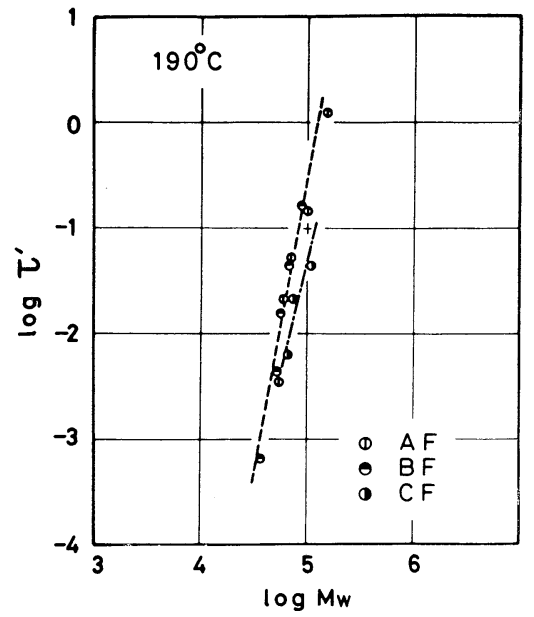

Fig. 6. Shift factor versus molecular weight of low density polyethylene fractions.

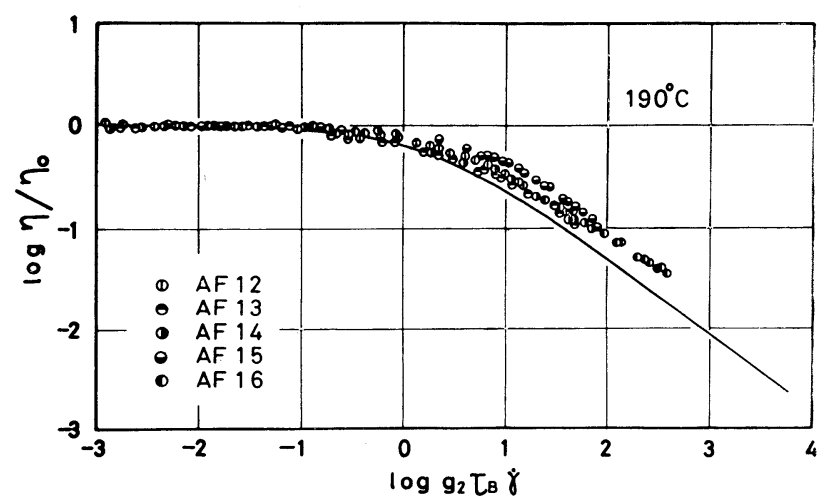

Fig. 7. The relation between $\eta / \eta_{0}$ and $g_{2} \tau_{\mathrm{B}} \dot{\gamma}$ of fractions AF series.

_ by Bueche-Harding's equation.

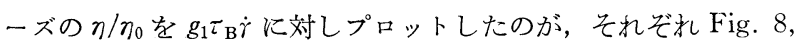
9,10 であり，長鎖分岐の効果を $g_{2}$ よりる $g_{1}$ で補正した場合の方 が, $\eta / \eta_{0}$ 対 $\dot{\gamma}$ の曲線の重社合わせは良姄であり，更には Bueche, Harding の式(5) に近い值を示す. Mendelson ${ }^{15)}$ らは LDPE 分 別物の場合にも分岐指数 $g_{1}$ のほか心分子量分布に依存するパラ メータを用いている．しかし，本研究の結果では分別物の場合に は分子量分布に依存するパラメータは必ずしも必要でないと考党 られる。

$\eta / \eta_{0}$ 対 $g_{1} \tau_{\mathrm{B}} \dot{\gamma}$ の関係で重㸚合せをしたとき, $\mathrm{AF}$ シリーズと $\mathrm{BF}$ シリーズのデータは互いによく一致するが， CF シリーズの データはこれらに厳密には一致しない。これは Fig. 8〜Fig. 10 のデータと式 (5) の曲線との一致の程度を比較するとよく分かる. このことは長鎖分岐の影響を単に分岐指数 $g_{1}$ で表現したためで あり, 更に厳密な解析には分岐の種類, 長さおよび数などに関す る知見が必要と思われる。

本研究に使用した LDPE 分別物の場合には分岐構造に関する 知見は十分ではないが，緩和時間 $\tau_{\mathrm{B}}$ の代りに，長鎖分岐の影響 を考虑した $g_{1} \tau_{\mathrm{B}}$ を用いることにより，分別物融液の非ニュート ン挙動は Bueche, Harding のマスターカーブにほぼ整理できると 考えられる。

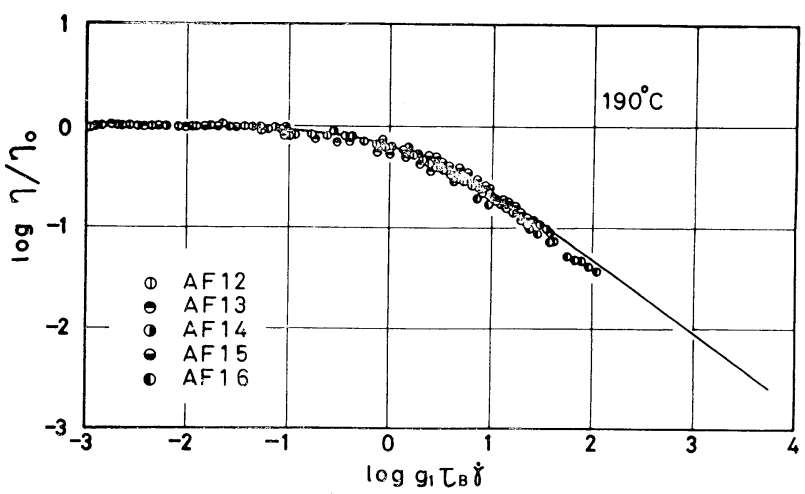

Fig. 8. The relation between $\eta / \eta_{0}$ and $g_{1} \tau_{\mathrm{B}} \dot{\gamma}$ of fractions AF series.

__ by Bueche-Harding's equation.

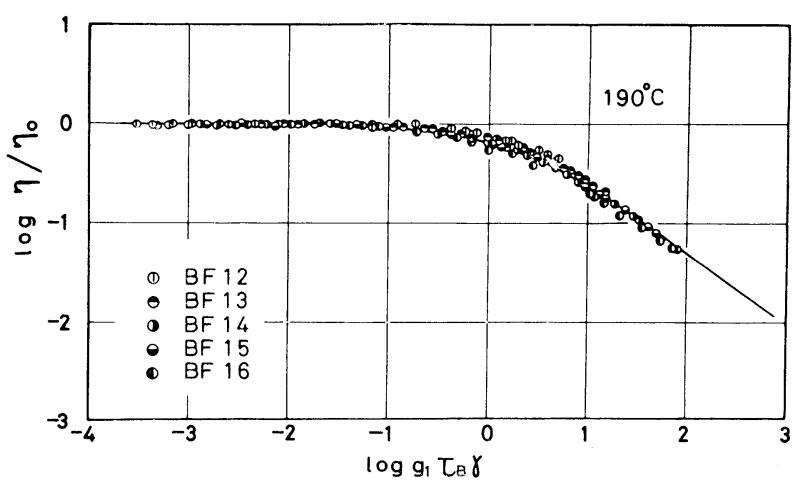

Fig. 9. The relation between $\eta / \eta_{0}$ and $g_{1} \tau_{\mathrm{B}} \dot{\gamma}$ of fractions $\mathrm{BF}$ series.

— by Bueche-Harding's equation.

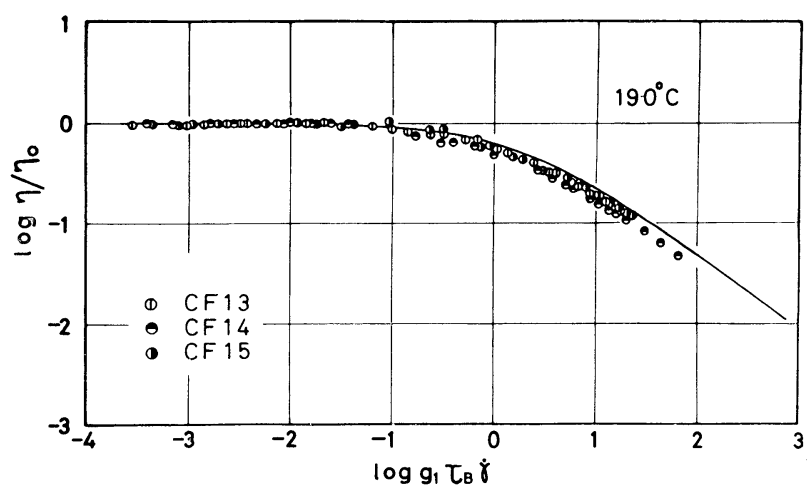

Fig. 10. The relation between $\eta / \eta_{0}$ and $g_{1} \tau_{\mathrm{B}} \dot{\gamma}$ of fractions CF series.

_ by Bueche-Harding's equation.

謝辞 実験を遂行するに当たり，御助力頂いた当研究所の方々 並びに酒井昌利氏（現三菱モンサント化成㑣）飞刘し謝意を表す るとともに, 本研究の発表を許可された会社当局に感謝いたしま す.

（昭和49年10月 3 日，第22回レオロジー討論会にて講演）

参考 文 献

1) Bagley, E.B., J. Appl. Phys., 28, 624 (1957). 
2) Rabinowitch, B., Z. Phys. Chem., 145, 1 (1929).

3) Tung, L.H., J. Polymer Sci., 24, 333 (1957).

4) Mendelson, R.A., W.A. Bowles, and F.L. Finger, ibid., A-2, 8, 105 (1970).

5) Kraus, G., and J.T. Gruver, ibid., 3, 105 (1965).

6) Long, V.C., G.C. Berry, and L.M. Hobbs, Polymer, 5, 517 (1964).

7) Bueche, F., J. Chem. Phys., 40, 484 (1964).

8) Zimm, B.H., and W.H. Stockmayer, ibid., 17, 1301 (1949).

9) Bueche, F., ibid., 20, 1959 (1952).

10) Graessley, W.W., ibid., 43, 2696 (1965)

11) Graessley, W.W., ibid., 47, 1942 (1967).
12) Sabia, R., J. Appl. Polymer Sci., 7, 347 (1963).

13) Bueche, F., and S.W. Harding, J. Polymer Sci., 32, 177 (1958).

14) Graessley, W.W., and J.S. Prentice, ibid., A-2, 6, 1887 (1968).

15) Mendelson, R.A., W.A. Bowles, and F.L. Finger, ibid., A-2, 8, 127 (1970)

16) Zimm, B.H., and R.W. Kilb, ibid., 37, 19 (1959).

17) Kilb, R.W., ibid., 38, 403 (1959).

18) Flory, P.J., and T.G. Fox, J. Amer. Chem. Soc., 73, 1904 (1951).

19) Trementozzi, Q.A., J. Polymer Sci., 23, 887 (1957). 